\title{
Temperature and moisture distribution in a highway in south-eastern Kazakhstan
}

\author{
Bagdat Teltayev ${ }^{1, *}$, and Elena Suppes ${ }^{1}$ \\ ${ }^{1}$ Kazakhstan Highway Research Institute, 2A, Nurpeissov St., Almaty, 050061, Kazakhstan
}

\begin{abstract}
The matters of investigation for water thermal regime of pavement and subgrade structures of the highways are especially important as the moisture and temperature distribution in pavement and subgrade layers impact greatly on their deformation and strength indicators. Experimental results, which can be obtained by special measurement devices, are primary ones for establishing of peculiarities and regularities for distribution and migration of heat and moisture in the mentioned structural elements of the highways. Special measurement devices are required to obtain such experimental data. The paper shows the results for analysis of temperature and moisture variation in points of pavement and subgrade of "Almaty-Bishkek" highway. Temperature measurement has been performed by set of special sensors. Regular temperature and moisture measurement have been performed for the period from September 18, 2015 to June 2, 2016. Regularities for temperature regime variation in points of pavement for 24 hours are coordinated with air temperature variations. Amplitude of vibration for temperature is decreased with the depth increase. Moisture in subgrade points is gradually decreased with the reduction of daily average air temperature.
\end{abstract}

\section{Introduction}

Condition and service life of highways is affected not only by mechanical forces, such as load from moving vehicles, but also natural climatic factors, among which temperature and moisture are of specific importance.

In Kazakhstan first research of water thermal regime for subgrade and pavements was started approximately in $60 \mathrm{~s}-70 \mathrm{~s}$ of the previous century. This research was mainly the experimental one; moisture was measured by usual way of filling the hole, selection of soil samples from it with further use of thermostatic weight method.

In the beginning of 1990s the works were started for the research of temperature regime, first for asphalt concrete pavements, and then for other structural layers of pavement and subgrade with the use of special designed sensors of transistor [1,2] and thermal resistance [3].

In 2010 KazdorNII started a new stage of more advanced study of water thermal regime for pavements and subgrade of a highway. In November of the same year 3 sets of special sensors were installed in 'Astana-Burabai" highway. Moreover, sensors of each set were

\footnotetext{
*Corresponding author: bagdatbt@ yahoo.com
} 
installed in different depths of the vertical hole, drilled in a multilayer pavement and subgrade of the highway. Temperature measurement is performed according to the principle of thermal resistance variation, and moisture measurement - according to principle of dielectric permeability. Such combines structure of sensors allows obtaining of information for temperature and moisture in points of road structure simultaneously.

In 2013 the sets of temperature and moisture sensors were installed into the constructions of highway, located in other climatic conditions (close to Oskemen, Atyrau, Turkestan and Almaty cities). The sensors work in automatic regime, they carry out temperature and moisture measurement in each hours and the obtained information is recorded into memory block. Measurements are performed for a long time, data results are recorded into memory block, and then they are transferred by noise-proof cable into interface. More detailed information regarding design of sensors and conditions of their installation can be obtained in the works [4-7].

This paper represents some results of experimental study for temperature and moisture distribution in pavement and subgrade of "Almaty-Bishkek" highway, related to the period of time from 18 September 2015 to 2 June 2016.

\section{Experimental section}

Temperature and moisture sensors were installed in the highway in June 2013. General view of one set for sensors and View of surface part for temperature and moisture automatic measurement system are shown in Figures 1 and 2. Experimental section is located near Almaty city (km 58+895) on "Almaty-Bishkek" highway. This road section relates to I technical category and has 4 lanes and it is in operation after reconstruction in 2005.

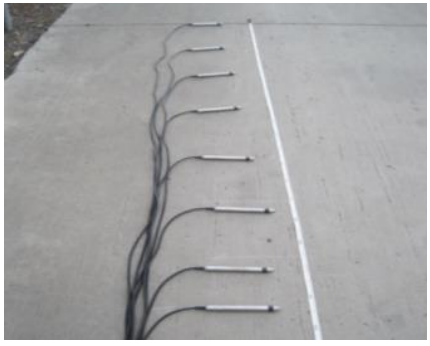

Fig. 1. General view of one set for temperature and moisture sensors.

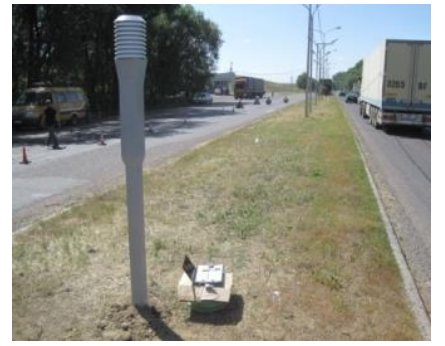

Fig. 2. View of surface part for temperature and moisture automatic measurement system.

Pavement structure of "Almaty-Bishkek" highway consists of the following layers: finegrained asphalt concrete $(5 \mathrm{~cm})$, coarse-grained asphalt concrete $(10 \mathrm{~cm})$, old fine-grained asphalt concrete $(6.5 \mathrm{~cm})$, old cold asphalt concrete $(15 \mathrm{~cm})$, sand gravel mix $(60 \mathrm{~cm})$. Subgrade soil is heavy sandy clay loam.

\section{Temperature regime}

Graphs for air temperature variation and temperature on the surface of asphalt concrete pavement are shown in Figure 3, and the graphs for temperature variation in points of subgrade of the road section are in Figure 4.

As it is seen from Figure 3, regularities of air temperature variation and temperature of surface of asphalt concrete coincide, i.e. temperatures of surface pavement vary in unison with air temperature. Decisive temperature excess of surface pavement over air temperature is observed in warm season, moreover, the higher air temperature the more difference in temperatures (as it is seen from the graph, maximum difference is $17-18^{\circ} \mathrm{C}$ ). In autumn season 
the difference between temperatures is decreased with gradual air temperature reduction and becomes equal to zero at a specific time moment, i.e. temperature on the pavement surface and air temperature are practically equal.

During the period of observations maximum fixed air temperature occurred in the first decade of October 2015 and was equal to $+30.5^{\circ} \mathrm{C}$. Minimum air temperature reached $22.4^{\circ} \mathrm{C}$ and occurred in the middle of February 2016. Duration of cold period, when average daily air temperature was mainly below zero and at average it was about 2 months.

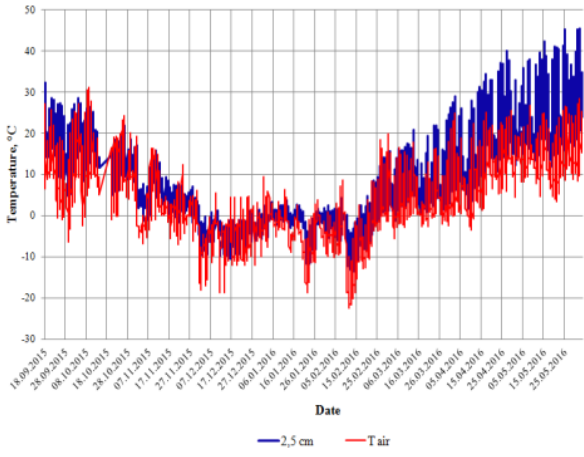

Fig. 3. Air temperature variation on the surface of asphalt concrete pavement of "AlmatyBishkek" highway.

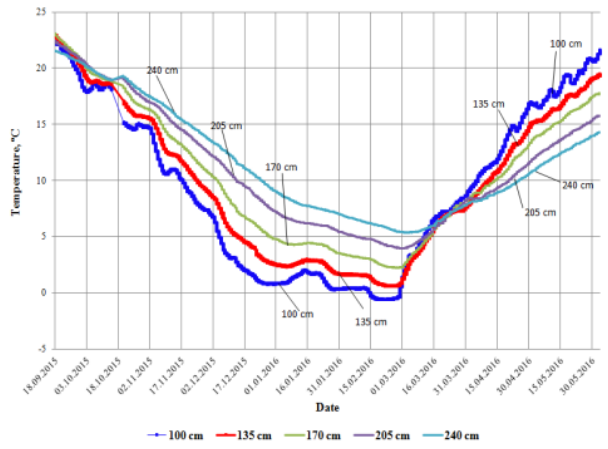

Fig. 4. Temperature variation in subgrade points of "Almaty-Bishkek" highway.

One should note that average daily air variations cause similar variations of temperature only in upper pavement layers (Figures 5 and 6), and in subgrade points, in the depth of 100 $\mathrm{cm}$ and below it, the average daily temperature variations are not observed. Here the temperature is decreased due to general air temperature reduction. Temperature variations in this depth and below it follow the linear law. Amplitudes of temperature variations in the subgrade layers copy each other and do not have abrupt jumps and drops. Temperature regime variation in subgrade is of seasonal character.

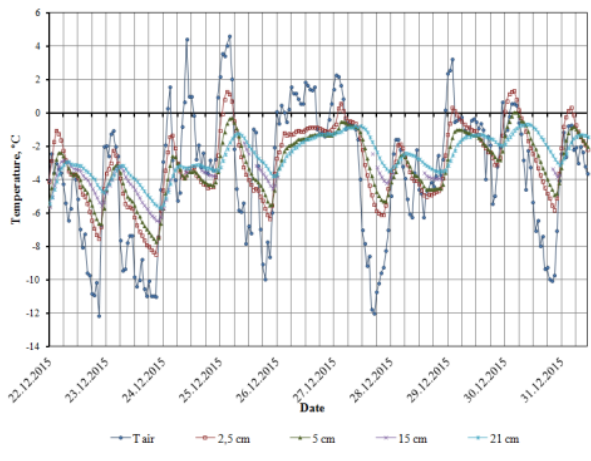

Fig. 5. Air temperature in pavement points of a highway for ten days (22.12.2015-31.12.2015).

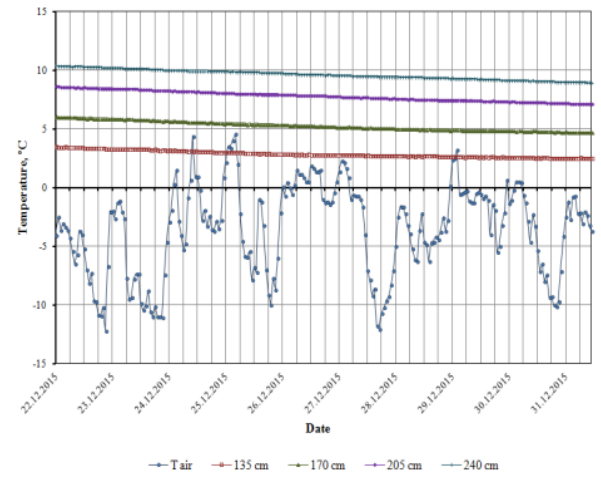

Fig. 6. Air temperature in subgrade points of a highway for ten days (22.12.201531.12.2015).

In winter season air temperature was reduced below than $-20^{\circ} \mathrm{C}$ (Figure 3). Frosting of upper layers of the base course starts from the beginning of the month of December 2015 and already to the end of January 2016 it covers all the pavement thickness (to the depth of 100 $\mathrm{cm})$. Starting from the middle of February, the frosting depth is decreased below $100 \mathrm{~cm}$, and frosting of subgrade surface begins. Maximum frosting depth during winter is equal to 118 
$\mathrm{cm}$. Temperature in points of subgrade bottom layers $(135 \mathrm{~cm}$ and below) during the observation period remain only positive.

\section{Moisture distribution}

Moisture distribution in subgrade soil impacts greatly on its strain and strength indicators. As an example let us give the graphs for moisture variation in subgrade layers (Figure 7). As it is seen from the Figure, moisture regime on this road section during the observation period (from 18 September 2015 to 2 June 2016) is stable on the whole. Daily moisture variations in subgrade points are not available.

Moisture on the subgrade surface in the depth of $100 \mathrm{~cm}$ during autumn season (from 18.09 .15 to 30.11 .15 ) varies within the range of $10-9.2 \%$. Sharp reduction of moisture indicator up to the value of $\mathrm{W}=6.9 \%$ occurs during the period of the biggest frosting (second half of the month of February), which is explained by transition of moisture part into solid condition (ice). Such reduction continued to the end of February. Moisture is gradually increased from the beginning of March. Except for the abovementioned time moments, moisture in this depth for the observation period varies within minor limits - from $8.4 \%$ to $10 \%$.

Moisture in other depths (from $135 \mathrm{~cm}$ and below) varies within minor limits and without abrupt jumps: thus, moisture in the depth of $135 \mathrm{~cm}$ varies only within the limits of $2 \%-$ from $7.1 \%$ to $8.8 \%$, in the depth of $205 \mathrm{~cm}-1.5 \%$ (from $7.7 \%$ to $9.3 \%$ ), in the depth of 240 $\mathrm{cm}-0.7 \%$ (from $7.4 \%$ to $6.7 \%$ ). Minimum moisture has been fixed in the depth of $170 \mathrm{~cm}$ where it varies from $5.3 \%$ to $7.2 \%$ (i.e. within the limits of $2 \%$ ).

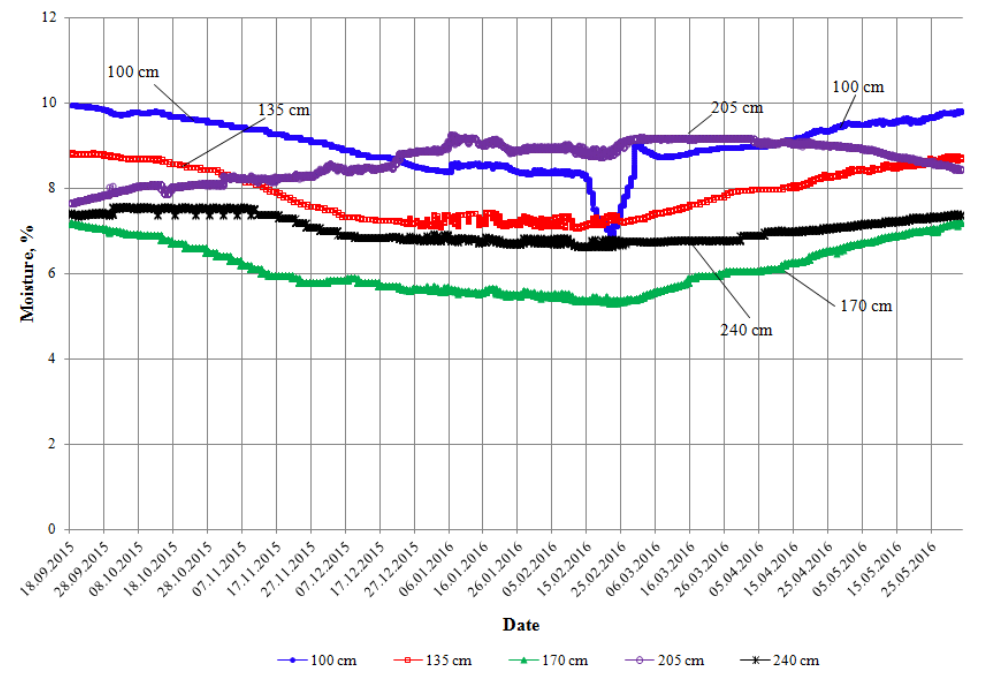

Fig. 7. Moisture variation in subgrade points of "Almaty-Bishkek" highway.

\section{Temperature and moisture distribution in the depth of subgrade of a highway}

Figures 8 and 9 represent the graphs, showing temperature distribution, and Figures 10 and 11 represent moisture distribution in the depth of subgrade. In cold period 9Figure 8) the temperature is gradually decreased in the course of time in all subgrade points, located up to the depth of $240 \mathrm{~cm}$. Thus, the temperature has been decreased for $1.8^{\circ} \mathrm{C}$ (from $+1.3^{\circ} \mathrm{C}$ to $0.5^{\circ} \mathrm{C}$ ) on the subgrade surface $(100 \mathrm{~cm}$ ) for 65 days (from 22 December to 24 February). For 
the same time period temperature reduction in the depth of $240 \mathrm{~cm}$ was $4.7^{\circ} \mathrm{C}$ (from $+10.4^{\circ} \mathrm{C}$ to $+5.7^{\circ} \mathrm{C}$ ).

It is clearly seen (Figure 10), that moisture is decreased in the whole depth of subgrade with temperature reduction. Thus, for the abovementioned time (65 days) moisture has been decreased for $1.2 \%$ and $0.1 \%$ respectively on the subgrade surface $(100 \mathrm{~cm})$ and in the depth of $240 \mathrm{~cm}$.

In warm season (Figure 9), temperature in all subgrade points is gradually increased with the air temperature increase during the time: temperature on the subgrade surface $(100 \mathrm{~cm})$ for 77 days (from 15 March to 30 May) has been increased for $14^{\circ} \mathrm{C}$ (from $+7^{\circ} \mathrm{C}$ to $+21^{\circ} \mathrm{C}$ ). For the same period the temperature increase in the depth of $240 \mathrm{~cm}$ was $8^{\circ} \mathrm{C}$ (from $+6^{\circ} \mathrm{C}$ to $\left.+14^{\circ} \mathrm{C}\right)$.

Moisture of subgrade has been also increased in the whole depth with temperature increase (Figure 11). Thus, moisture on the subgrade surface $(100 \mathrm{~cm})$ and in the depth of $240 \mathrm{~cm}$ has been increased for $1 \%$ and $0.6 \%$ respectively for the abovementioned period.

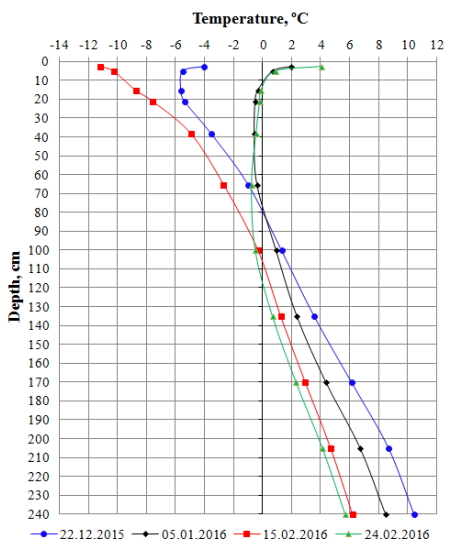

Fig. 8. Temperature distribution in the depth of subgrade in cold season (from 22.12.2015 to 24.02.2016).

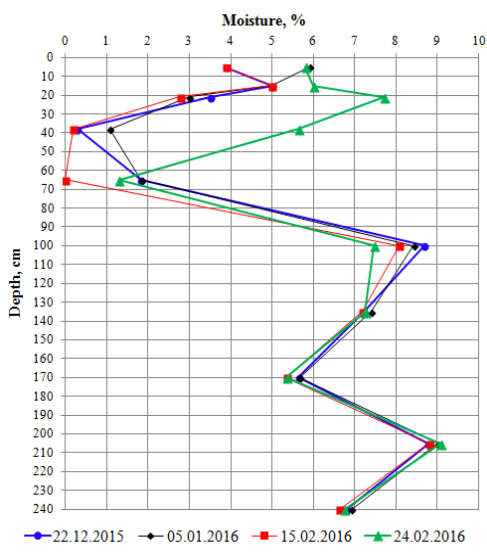

Fig. 10. Moisture distribution in the depth of subgrade in cold season (from 22.12.2015 to 24.02.2016)

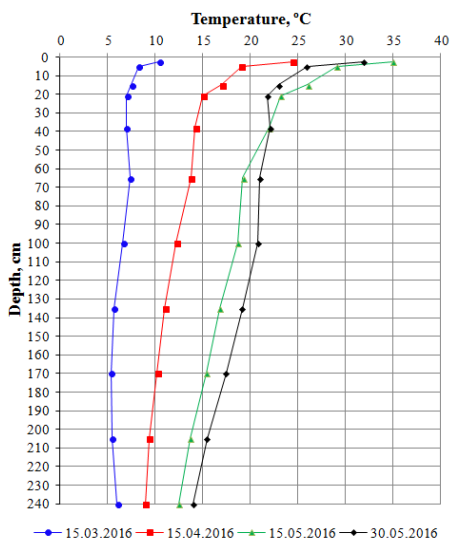

Fig. 9. Temperature distribution in the depth of subgrade in warm season (from 15.04.2016 to 15.07.2016).

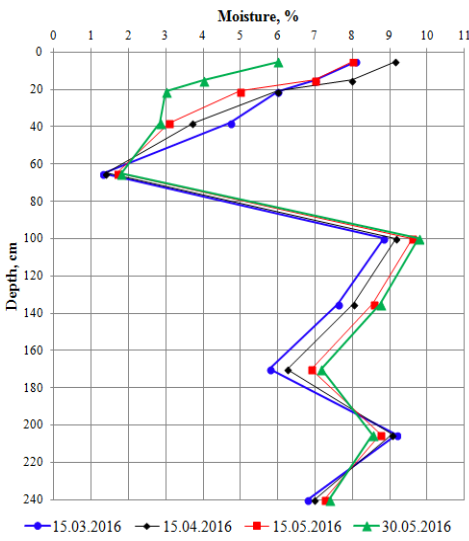

Fig. 11. Moisture distribution in the depth of subgrade in warm season (from 15.03.2016 to 30.05.2016) 


\section{Conclusion}

1) Subgrade frosting of "Almaty-Bishkek" highway for winter season 2015-2016 occurred only in its upper part, which certifies about warm winter. Period for subgrade soil frosting is about 2 weeks; the frosting depth is $118 \mathrm{~cm}$;

2) Solar radiation has a great impact on formation of temperature field in road structure of the region. Thus, solar radiation affects the temperature in asphalt concrete layers in warm seasons of the year, and the difference between air temperature and temperature of pavement surface in daytime reached $+17.0^{\circ} \mathrm{C} \ldots+18.0^{\circ} \mathrm{C}$;

3) Regularities for temperature regime variation in pavement points for 24 hours are strictly coordinated with air temperature variations. Amplitude of vibration for temperature is decreased with the depth increase, it approaches zero with reaching the depth of $100 \mathrm{~cm}$;

4) Moisture rate is mainly not high in subgrade layers for the observation period (from 18 September 2015 to 2 June 2016). Maximum moisture value has been recorded in the depth of $100 \mathrm{~cm}$, where the moisture indicator is within the range of $10 \%$;

5) Temperature in subgrade points is decreased to negative values with the average daily air temperature decrease. And this, in its turn results in moisture decrease in subgrade points which is explained by transition of moisture part into solid condition (ice).

\section{References}

1. B. Teltaev, Sh. Aytaliev, Ed. Acad, Deformations and stresses in flexible pavement structures (1999)

2. B. Teltaev, S. Burkovskiy, K. Kulmanov, Collection of materials: Deposited research works 4(6488-Ka95) (1995)

3. Sh. Aytaliev, B. Teltaev, K. Aytbaev, H. Tursumbekova, Bul. HEI. Const. 12, 66-70 (2003)

4. B. Teltayev, E. Suppes, Proceedings of the 19th Int. Conf. Soil Mech. Geotech. Eng. 14 (2017)

5. B. Teltayev, A. Baibatyrov, E. Suppes, The 15th Asian Reg. Conf. Soil Mech. Geotech. Eng., 1664-1668 (2015)

6. B. Teltayev, E. Suppes, Freezing characteristics of a highway subgrade, Sci. Cold Arid Reg. 9(3), 325-330 (2017)

7. B. Teltayev, E. Suppes, Geomech. Eng. 13(5), 793-807 (2017) 